\title{
OS DIFERENTES CONCEITOS DE DIVISÃO À LUZ DA TEORIA DA FORMAÇÃO DAS AÇÕES MENTAIS: A SURDEZ EM FOCO
}

\section{THE DIVISION OF DIFFERENT CONCEPTS IN THE LIGHT OF THE THEORY OF MENTAL TRAINING ACTIONS: DEAFNESS IN FOCUS}

\author{
Thamires Belo de Jesus, Edmar Reis Thiengo \\ Instituto Federal do Espírito Santo \\ E-mail: thamiresbelo@yahoo.com.br, thiengo.thiengo@gmail.com
}

\section{Resumo}

O eixo central deste estudo surgiu da necessidade de elaborar práticas pedagógicas inclusivas para o ensino e aprendizagem de matemática para alunos surdos. Este estudo objetiva-se discutir diferentes conceitos de divisão com base na comparação de figuras geométricas de forma a verificar como figuras de maior área podem ser construídas com figuras de menor área. Os dados foram produzidos por meio de uma intervenção realizada com uma aluna surda do 8 o ano do Ensino Fundamental de uma escola municipal localizada em Vitória, ES. Foram utilizados como instrumentos de pesquisa, o material pedagógico "Escala Algébrica", Formas geométricas, além de atividade que envolvem o algoritmo da divisão. As estratégias que englobam este estudo, foram elaboradas com base na Teoria da Formação das Ações Mentais por Etapas, criada por Piotr Galperin. Observamos indícios da construção de conceitos nos planos material, da linguagem externa e mental, constituindo-se evidências de aprendizagem. Verificamos que o Material Pedagógico "Escala Algébrica" influenciou como mediador entre a aluna surda, o professor e o objeto de ensino em questão e atuou como potências do desenvolvimento mental da aluna surda.

Palavras-chave: ensino de Matemática para surdos. educação matemática e inclusão. divisão.

\begin{abstract}
The central axis of this study arose from the need to develop inclusive teaching practices for teaching and learning of mathematics to deaf students. This study aims to discuss different division of concepts based on the comparison of geometric figures in order to see how larger area figures can be built with smaller area figures. The data was produced through an intervention performed with a deaf student of the 8th grade of elementary school to a public school located in Vitoria, ES. They were used as research tools, teaching materials "Algebraic Scale", geometric shapes, as well as activities involving the division algorithm. The strategies that comprise this study were prepared based on the theory of formation of mental actions by Steps, created by Piotr Galperin. We observed evidence of building concepts in materials plans, foreign language and mental, being evidence of learning. We found that the Pedagogical Material "Algebraic Scale" influenced as a mediator between the deaf student, the teacher and the teaching of subject matter and served as powers of mental development of the deaf student.
\end{abstract}

Palavras-chave: Math education for deaf people. Math education and inclusion. division. 


\section{INTRODUÇÃO}

Fruto de inquietações inerentes a uma pesquisa de mestrado realizada no ano de 2013, este estudo apresenta resultados de investigações compartilhadas com uma aluna surda que frequenta uma escola municipal do município de Vitória - ES. São destaques desta pesquisa o ensino de matemática e inclusão de alunos surdos em escolas regulares.

Este texto traz algumas reflexões acerca do movimento surdo e a educação de surdos, posteriormente destaca-se alguns apontamentos teóricos-metodológicos que permearam as analises e discussões dos dados, seguindo da descrição de uma das atividades desenvolvidas na pesquisa, finalizando com as reflexões e considerações finais.

Para este estudo, nos pautaremos na concepção da escola inclusiva descrita por Almeira (2005). Segundo o autor "Ao pensarmos a escola inclusiva é fundamental pensarmos a prática pedagógica em sala de aula, uma prática diferenciada que atenda a multiplicidade vivenciada" (ALMEIDA, 2005, p. 195).

Neste sentido, buscaremos olhar para o aluno surdo como um sujeito diferente dentro de suas particularidades, e nos apoiaremos em práticas que possibilitem que estes alunos consigam compreender conceitos matemáticos.

\section{O MOVIMENTO SURDO E A EDUCAÇÃO}

Os sujeitos que passam pela escola carregam marcas deixadas por ela. Entretanto, quando se trata da comunidade surda, essas marcas são ainda mais evidentes, visto que, esta comunidade tem a escola como espaço de possibilidades de existência (LOPES; VEIGA-NETO, 2006). Nesse contexto, a escola de surdos transforma-se em um espaço que contribui para a manutenção das lutas da comunidade surda. É um local onde os surdos podem utilizar sua língua materna e lutar pelos seus ideais. Porém, Lopes e Veiga-Neto (2006, p. 94) afirmam que:

A escola de surdos, principalmente na década de 1990, foi um espaço de 
muitas mudanças conquistadas pelos surdos e por ouvintes que militam na causa surda. Ela era vista como um lugar de diferenças onde os surdos poderiam ser atendidos em suas especificidades linguísticas e culturais. Com o fortalecimento do movimento surdo e com a necessidade de os surdos ocuparem outros espaços sociais e no mercado de trabalho, tal escola começou a ser questionada - não no que se refere ao espaço cultural, mas ao que se refere ao ensinado nela.

De acordo com os estudos de Santos (2005, p. 56), “o sucesso escolar do aluno surdo não é definido a partir do tipo de oferta educativa". A sustentação da escola especial para surdos não se sustenta sob o argumento de que a escola regular é fracassada diante do surdo, nem tampouco, a escola regular garante seu aspecto de inclusão com base nos seus espaços ofertados. Ambas as ofertas encontram barreias e se deparam com fracassos e sucessos.

Para Santos (2005, p. 57), “pensar nestas ofertas, de forma crítica e consciente, é admitir que não existe um surdo genérico ou aluno genérico, um protótipo, ou seja, um único caminho possível". Além disso, a autora nos faz a seguinte indagação: "Determinando qual o tipo de oferta educativa não estariam fazendo a mesma escolha feita no Congresso de Milão?" Visto que:

As atas finais do Congresso de Milão, realizado em 1880, definiram novas políticas educacionais e indicavam que: $\mathrm{O}$ congresso, considerando a incontestável superioridade da palavra sobre os signos para devolver o surdo à sociedade para dar-lhe um melhor conhecimento da língua, declara que o método oral deve ser preferido ao da mímica para educação e instrução dos surdos-mudos (...). O Congresso considerando que o uso simultâneo da palavra e dos signos mímicos têm a desvantagem de inibir a leitura labial e a precisão de ideias, declara que, o método oral puro deve ser preferido. (GRÉMION, 1991, apud, SKLIAR, 2010, p. 37)

Nesse sentido, é preciso pensar em ofertas escolares de forma crítica, onde se busquem 
estratégias pautadas na pluralidade de culturas, objetivando uma formação crítica do sujeito que possibilite uma participação efetiva no seu meio social.

Em relação ao contexto histórico, Lopes e Veiga-Neto (2006, p.85) afirmam que:

Na relação com o ouvinte, o surdo foi ensinado a olhar-se e a narrar-se como deficiente auditivo. A marca da deficiências determinou, durante a história dos surdos e da surdez, a condição de submissão ao normal ouvinte. Dessa história de submissão, criaram-se práticas corretivas derivadas de saberes que informam e classificam os sujeitos dentro de fases de desenvolvimento linguístico, cronológico e de perda auditiva (grifos do autor).

Algumas destas marcas históricas penduram até os dias atuais, como por exemplo a submissão do surdo ao normal ouvinte e as práticas corretivas quanto a aquisição da linguagem. A escola, enquanto espaço inclusivo, deve possibilitar que o surdo se relacione com o conhecimento matemático a partir de suas particularidades e habilidades, como por exemplo, por meio da língua de sinais. Acerca da língua primária utilizada pelos surdos, a língua de sinais, Quadros (2004) afirma:

As línguas de sinais são, portanto, consideradas pela linguística como línguas naturais ou como um sistema linguístico legítimo e não como um problema do surdo ou como uma patologia da linguagem. Stokoe, em 1960, percebeu e comprovou que a língua de sinais atendia a todos os critérios linguísticos de uma língua genuína, no léxico, na sintaxe e na capacidade de gerar uma quantidade infinita de sentenças (QUADROS, 2004, p. 30).

Isso nos permite questionar práticas corretivas que objetivam "ouvintizar" os surdos, ou seja, torna-los mais próximos dos ouvintes. Os surdos possuem uma língua legítimas e por meio dela podem desenvolver conhecimentos, inclusive sobre a matemática. Complementando as ideias postas por Quadros (2004), Lacerda (1998) salienta que: 


\begin{abstract}
A língua de sinais é considerada a mais adaptada à pessoa surda, por contar com a integridade do canal visogestual. Porque as interações podem fluir, a criança surda é exposta, então, o mais cedo possível, à língua de sinais, aprendendo a sinalizar tão rapidamente quanto as crianças ouvintes aprendem a falar. Ao sinalizar, a criança desenvolve sua capacidade e sua competência linguística, numa língua que lhe servirá depois para aprender a língua falada, do grupo majoritário, como segunda língua, tornando-se bilíngue, numa modalidade de bilinguismo sucessivo (LACERDA, 1998, p. 5).
\end{abstract}

Uma vez reconhecida as capacidades de aprendizagens dos surdos é preciso questionar o papel da escola perante a escolarização destes sujeitos. Assim, concordamos com Carvalho (2008, p.46) o espaço de ensino e aprendizagem deve ser "uma escola para todos, com todos, mas uma escola que, além da presença física, assegure e garanta aprendizagem e participação".

Reconhecendo que a escola é constituída de sujeitos diferentes, dentre eles os surdos, acreditamos que o ensino possa ser trabalhado a partir de metodologias diferenciadas. Assim, de acordo com as necessidades e habilidades do indivíduo, serão pensados métodos de ensino particulares.

\title{
3. FORMAÇÃO DAS AÇÕES MENTAIS POR ETAPAS
}

Este texto é embasado teoricamente pela Teoria da Formação das Ações Mentais por Etapas, de Piotr Galperin. Este autor elaborou um dos mais detalhados estudos a respeito das etapas de ações mentais a partir da atividade externa. Sua teoria explica a assimilação do conhecimento em etapas fundamentais como passagem da experiência social para a experiência individual (NUÑEZ; PACHECO, 1998).

Segundo Nuñez e Pacheco (1998), na essência dessa teoria, primeiro deve-se encontrar a forma adequada da ação; segundo, encontrar a forma material de representação da ação; e, 
terceiro, transformar essa ação externa em interna. Esse processo de internalização da atividade externa em interna é concebido por um ciclo de aprendizagem, com destaque a etapas funcionais. E que, apesar da separação didática dessas etapas para melhor entendimento do processo, elas seguem um processo dialético, de influência mútua, não configurando um modelo linear de etapas que segue uma mesma direção. As etapas que compreendem esse processo de internalização de atividades externas materiais são: Motivacional, Estabelecimento da base orientadora da ação, Formação da ação no plano material, Formação da ação no plano da linguagem externa, Mental.

Em síntese, a forma sofre mudanças da etapa material para a verbal e por último para a mental, tendo como princípio norteador uma motivação inicial. Nesse processo a independência progride das ações sociais compartilhadas, ou seja, com a ajuda de outros pares, com um desenvolvimento maior em relação ao conteúdo estudado, até chegar a uma ação independente praticada pelo sujeito.

Segundo Bassan (2012) a etapa motivacional objetiva preparar os estudantes para a apropriação de novos conhecimentos e, por isso, é trabalhada com eles a necessidade de aprender, de encontrar no estudo um sentido humanizador. A fase Motivacional precede a primeira etapa proposta por Galperin, a fase de elaboração da Base Orientadora da Ação (BOA), que pode ser definida como "o conjunto de circunstâncias pelo qual o estudante se orienta durante a realização da ação" (BASSAN, 2012, p.67).

A realização das ações é desenvolvida pelo sujeito por meio de três etapas, a considerar: material, linguagem externa e mental. A etapa materializada (modelos dos objetos reais) ou material (objetos reais) caracteriza-se pela presença da ação sobre materiais concretos, pela manipulação de objetos, por meio da interação direta com tais objetos ou por meio de suas representações materiais - imagens, fotos, mapas (BASSAN, 2012).

A etapa verbal é guiada pelo uso da linguagem. Apesar de alguns autores (BASSAN, 2012; 
NUÑEZ; PACHECO, 1998; DUARTE, 2011; REZENDE; VALDES, 1993) apresentarem esta etapa como "fase verbal" ou "etapa verbal", ela foi criada por Galperin com base nas discussões sobre o significado da linguagem.

Nesse sentido, ao analisar as discussões sobre a linguagem dentro da Teoria HistóricoCultural, apoiada e seguida por Galperin, vemos que ela é constituída por um sistema organizado de sinais que serve de comunicação entre os sujeitos. Assim, ela pode ser estabelecida de forma verbal ou não verbal, pois ambas são capazes de expressar sentidos e se utilizam de signos. Na linguagem verbal, os signos são as palavras. Elas são expressas de forma oral ou escrita; e na linguagem não-verbal, são utilizados outros sinais para a comunicação, como os gestos, as expressões faciais, os desenhos, as pinturas, as danças, entre outros elementos.

Com base nas considerações anteriores, destacamos que, a discussão de Galperin (1989) gira em torno de uma etapa permeada pela linguagem, portanto nos permite considerar as linguagens verbais ou não verbais. Por esse motivo, encontramos possibilidades de conciliar a Teoria de Galperin com as atividades envolvendo alunos surdos ${ }^{1}$.

Por fim, na etapa Mental "a linguagem externa é substituída pela linguagem interna, que proporciona ao sujeito - estudante - a possibilidade de estruturar e reestruturar seu pensamento" (BASSAN, 2012, p. 73). Assim sendo, o aluno desprende-se das ações materializadas ou materiais e das ações da linguagem e converte-as em ações mentais, levando também a desvinculação dos signos externos, dando lugar aos signos internos. Diante destes apontamentos, foram elaboradas atividades e estas foram investigadas junto a professores e uma aluna surda.

1 Apesar das discussões que envolvem a linguagem verbal e não-verbal, os autores que citamos neste estudo, usam o termo "etapa verbal" ou "discursos orais ou escritos". Não encontramos estudos brasileiros que utilizem a Teoria da Formação das Ações Mentais com sujeitos que fazem uso da linguagem não-verbal, desta forma, acreditamos ser este o motivo para a consideração das terminologias apresentadas pelos autores. Nesse sentido, ao tratar da etapa verbal com base no discurso oral ou escrito, estaremos considerando também a possibilidade deste discurso ser realizado por meio da linguagem não-verbal, especificamente pelo uso da Libras. 


\section{PROCEDIMENTOS METODOLÓGICOS}

Esse estudo insere-se numa abordagem de pesquisa qualitativa. A Teoria da Formação das Ações Mentais por Etapas foi utilizada como base teórica e metodológica para toda a investigação.

A pesquisa completa contou com 10 atividades, sendo incialmente aplicada uma atividade diagnóstica inicial, seguindo de 8 atividades que perpassaram por todas as quatro etapas estabelecidas por Galperin (motivacional, material, verbal e mental) e, por fim, foi realizada uma atividade diagnóstica final. Porém, para este artigo, apresentaremos apenas uma das atividades realizadas com a aluna.

A pesquisa foi realizada numa escola municipal de Vitória - ES durante o ano de 2013 com uma aluna surda do 8 o ano do ensino fundamental que apresenta surdez congênita ${ }^{2}$, profunda e bilateral. Esta aluna iniciou o contato com a Libras em 2011 e é oralizada. Para a realização do estudo ainda contamos com o Intérprete de Libras/Língua Portuguesa (TILS) e um instrutor surdo. A aluna receberá o nome fictício de Lia neste texto.

Para a produção e registro dos foram utilizados entrevistas, questionários, registro em diário de bordo, fotografias, gravações de áudios, atividades, observação participante e grades de observação. De forma a preservar a identidade dos participantes usaremos nomes fictícios para identificá-los. Os dados foram analisados com base na Teoria das Ações Mentais por Etapas.

\section{EM AÇÃO: OS DIFERENTES CONCEITOS DE DIVISÃO}

Segundo Centurión (2006) "a divisão está ligada a duas ideias: a ideia de repartir em partes iguais e a ideia de medir, ou seja, a de verificar 'quantos cabem'” (p.192). Focaremos na segunda ideia apresentada por Centurion (2006), a ideia de medir.

2 Quando a criança nasce surda. As causas podem ser o uso medicamentos tomados pela gestante, doenças adquiridas durante a gestação, como sífilis e toxoplasmose, ou por causa hereditária. 
Quantas vezes cabe o 12 dentro do 48? Esse exemplo, que ilustra a ideia de divisão enquanto processo de medir, também pode ser trabalhado num contexto da geometria. Como no exemplo seguinte.

Figura 1. Segmentos de reta

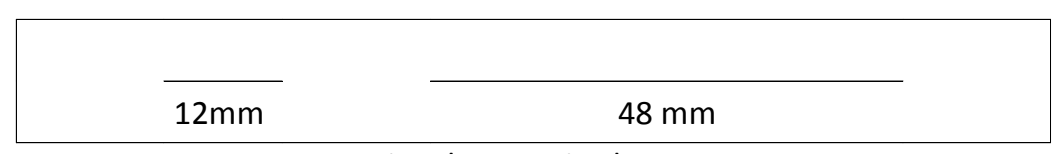

Fonte: arquivo da pesquisadora.

A figura 33 ilustra dois segmentos de reta. O segmento menor tem um comprimento de $12 \mathrm{~mm}$ e o maior de $48 \mathrm{~mm}$. Com base nessas informações é possível dividir o maior segmento utilizando como unidade de medida o menor segmento, ou seja, verificar quantas vezes o menor segmento cabe dentro do maior segmento. A realização desse processo pode ser ilustrada da seguinte forma:

Figura 2. Divisão de segmentos.

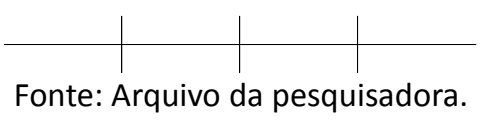

Conforme figura 34 , o menor segmento de $12 \mathrm{~mm}$ cabe exatamente 4 vezes dentro do segmento de comprimento igual a $48 \mathrm{~mm}$. Mas afinal, o que significa afirmar que cabe 4 vezes? Na verdade, o processo realizado foi uma divisão, como medição. A resposta encontrada (cabe 4 vezes) é o resultado de uma divisão de dois segmentos com comprimentos conhecidos, ou ainda, 4 é resultado da divisão de 48 por 12 . Por tanto, o processo de verificar quantas vezes o número 12 cabe dentro do 48 é uma forma de efetuar uma divisão. Trata-se de uma ideia de divisão diferente de outra noção, divisão como repartição em partes iguais. Nesta segunda ideia de divisão, o objetivo distribuir 48 balas igualmente para 12 alunos. Nesse exemplo, cada aluno dos 12 alunos irá receber um total de 4 balas. 
É importante notar que apesar dos valores serem os mesmos, trata-se de dois problemas distintos, envolvendo processos distintos da divisão. O primeiro enquanto processo de medição e o segundo em repartir em partes iguais. Ainda segundo Centurion (2006) a ideia de divisão como processo de medir, é menos abordada em sala de aula em relação a processo de divisão enquanto repartição em partes iguais. Nota-se, portanto, a importância dessa abordagem com nossos alunos.

Observa-se nos exemplos anteriores, que o ensino de geometria pode contribuir para a abordagem de outros conteúdos matemáticos. Além disso, por meio da geometria, o aluno pode vivenciar situações em que a divisão não acontece apenas com números, mas também como formas geométricas.

Solicitamos que Lia resolvesse ao seguinte problema: "quantos $\triangle$ são necessários para formar um $\square$ ?"3 Em seguida perguntamos a Lia se ela havia feito uma divisão e ela disse que não. Então perguntamos a ela o que era "divisão". Ela então procurou um registro no caderno e apresentou o que está ilustrado na figura a seguir.

Figura 3. Exemplos de divisão apresentados por Lia.

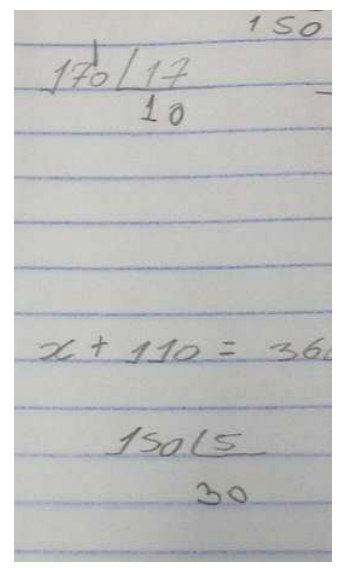

Fonte: arquivo da pesquisadora.

3 Ressaltamos que o triângulo e hexágono utilizados na atividade são regulares e os lados dos respectivos polígonos são iguais. 
O conceito que Lia tinha sobre divisão estava relacionado apenas à ideia de repartir em partes iguais. E mais, a divisão para Lia existia apenas com números. Diante dessa situação, utilizamos outro Material Pedagógico, a escala algébrica ${ }^{4}$, para trabalhar os dois diferentes conceitos de divisão conforme proposto por Centurión (2006).

Num primeiro momento Lia interagiu com o material a fim de se familiarizar com o mesmo. Ao saber que iriamos discutir divisão com este material a mesma indagou: "divisão de letras?", se referindo as letras registradas em cada peça do material. Acreditamos que a dúvida de Lia deve-se ao fato da mesma conceber a divisão apenas com um algoritmo envolvendo algarismos, como ilustrado na figura 3.

Figura 4. Escala algébrica.

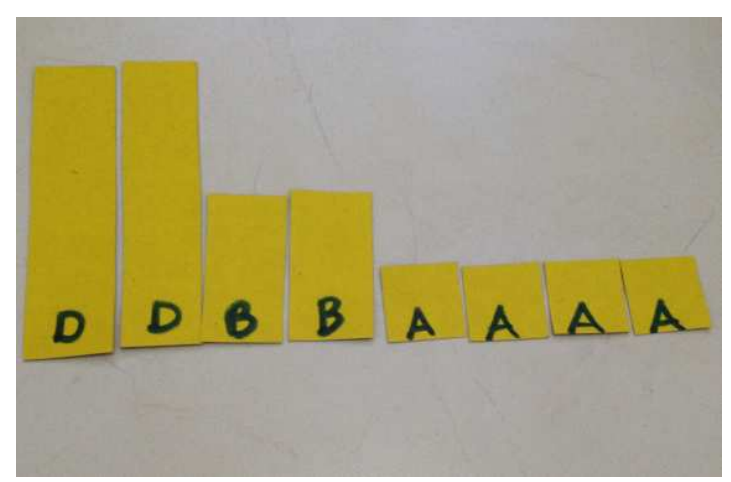

Fonte: Arquivo da pesquisadora.
Figura 5. Comparando medidas.

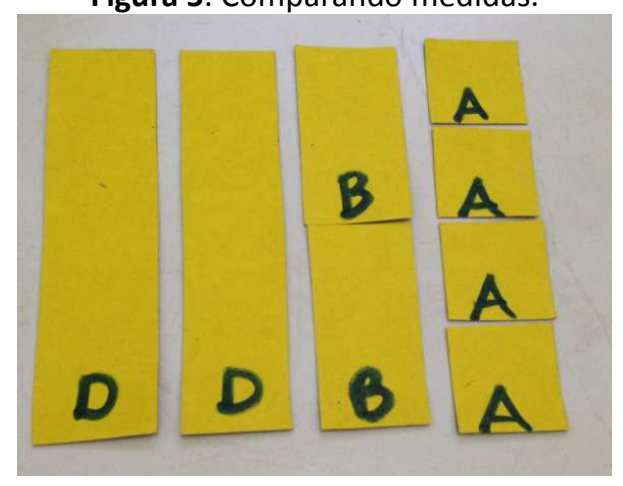

Fonte: Arquivo da pesquisadora.

Figura 6. Medindo formas.

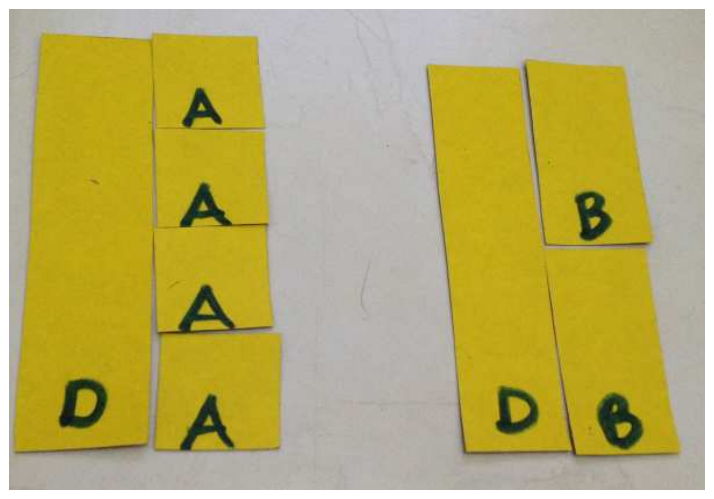

Fonte: Arquivo da pesquisadora.

4 Esse material foi confeccionado anteriormente e validado junto a professores e pedagogos num minicurso realizado na Secretaria Municipal de Educação do Município de Serra. Na ocasião foi utilizado para trabalhar a construção do conceito de número. 
Com o uso do material apresentado nas figuras 4, 5 e 6, efetuamos comparações de medidas. Lia conseguiu verificar que, utilizando 4 peças de tamanho $A$ era possível construir uma peça de tamanho D. E ainda, ao verificar quantas peças de tamanho A cabem dentro da peça $D$, ela estava fazendo uma divisão da peça $D$ em quatro partes menores, cada uma dessas partes com tamanho igual a A. Sobre esta experiência pautada pela interação com o meio, Kaleff (1998, p.15) salienta que

É a partir das experiências pessoais com a forma, cor, textura, dimensões e a manipulação de um objeto físico que as imagens mentais dele serão construídas, permitindo sua visualização ainda que na ausência deste, assim como sua representação por meio de modelos concretos ou desenhos.

Ao final da investigação, Lia disse que as peças ilustradas nas figuras 36, 37 e 38 eram parecidas com uma barra de chocolate. E que ela sempre dividia a barra de chocolate com os amigos.

Ao associar as peças A, B e D, a uma barra de chocolate, Lia executou uma ação no plano da linguagem externa e mental, visto que, mesmo sem ter acesso à forma material da barra de chocolate ela conseguiu buscar a imagem mental desse objeto e relacioná-la ao Material Pedagógico que estávamos utilizando. O processo pelo qual o sujeito executa um ação mentalmente (buscar imagens da sua experiência de vida e relacioná-las a novos objetos) e depois expressa essa ação por meio da linguagem, no caso da Lia por meio da Libras, é destacado como a construção de conceitos (GAPERIN, 1989; NUÑEZ; PACHECO, 1998).

Portanto, essa ação mostrou que "o desenvolvimento do pensamento é determinado pela linguagem, isto é, pelos instrumentos linguísticos do pensamento e pela experiência sóciocultural da criança" (VYGOTSKY, 2001, p. 44).

Lia, buscou por meio de sua experiência sócio-cultural um elemento de sua realidade e 
associou ao pensamento geométrico daquele momento.

Figura 7 - Barra de chocolate

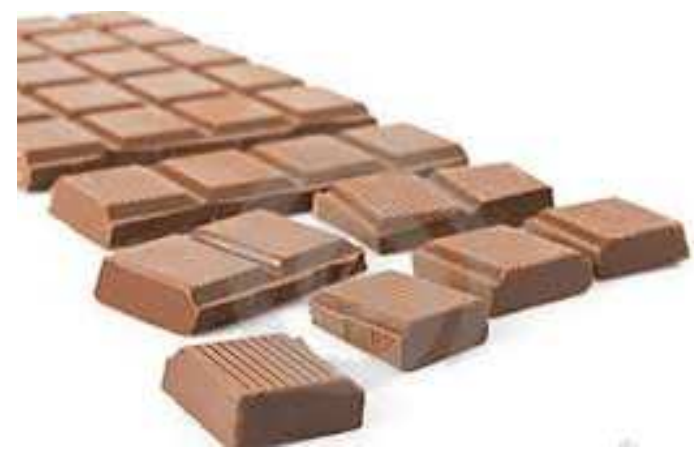

Fonte: http://pt.dreamstime.com/fotografia-de-stock-barra-de-chocolate-quebrada-do-leite-image8117282. Acesso em: 10 jan. 2014.

Ao observar as figuras 4 e 7 podemos realmente ver uma relação. Percebemos então, que, ao afirmar que sempre dividia a barra de chocolate com os amigos, Lia demostrou ter certa consciência sobre a ação de dividir, enquanto divisão em partes iguais, mas até então não conseguia relacionar essa ação com o conteúdo matemático divisão.

Foi então que mostramos para Lia que o processo de divisão não acontece apenas com os números, e que, frequentemente estamos realizando divisões, seja verificando quantos cabem ou dividindo em partes iguais.

Retomamos a atividade, e verificamos junto da Lia que, ao usar o triângulo como unidade de medida e verificar quantos dele cabem dentro do todo, ou seja, do hexágono, trabalhamos com a ideia de divisão, pois ela verificou quantas vezes cabe o triângulo dentro do hexágono. Foi um momento especial, pois verificamos, junto da Lia, que a divisão não era apenas os algoritmos que constavam no seu caderno, mas estão muito mais presentes em nossas vidas, e muitas vezes nem nos damos conta de que estamos realizando tais operações.

Ao final da investigação, solicitamos que lia expressasse por meio da Libras o que aprendeu com a atividade e a mesma salientou "Eu lembrar sempre de divisão. Gosto de Chocolate. 
Sempre que comer chocolate lembrar da divisão nova". Cabe esclarecer que Lia categorizou a divisão enquanto ideia de medir como "divisão nova" por se tratar de um conceito novo para ela.

Segundo a Teoria das Ações Mentais, o momento e que o sujeito consegue assimilar conceitos novos e diferenciá-los dos já aprendidos ampliando suas ações mentais, ou seja, sua aprendizagem.

\section{UM ANO DEPOIS...}

Ao retornar na escola no ano de 2014, um ano depois da realização da pesquisa, avistei a Lia na sala do Atendimento Educacional Especializado (AEE) comendo chocolate. Ao dialogar com a aluna e perguntar sobre as aulas de Matemática fui surpreendida com suas recordações. Lia se remeteu às atividades que foram desenvolvidas durante a pesquisa sobre o conteúdo de divisão e nos surpreendeu com palavras: "chocolate, lembra, a divisão nova".

Esta simples e pequena frase releva que os diferentes conceitos de divisão trabalhados durante a pesquisa no ano de 2013 com base na Teoria das Ações Mentais por Etapas, proporcionaram algum sentido para Lia.

Este episódio nos remete as palavras de Bassan (2012) a respeito do processo de educação, como processo de humanização dinamicamente:

implica a socialização do homem pela sua inserção em atividades com o outros e com os objetos, fatos e ventos de sua realidade, com os quais se relaciona, apropriando-se do conteúdo de sua atividade e transformando as qualidades inerentes ao objeto dessa atividade em qualidades internas de seu psiquismo. (ibid, p.09).

Com base nas palavras de Lia, algumas evidências podem ser consideradas. Ela se apropriou 
dos diferentes conceitos de divisão, encontrou formas próprias para recordar dos conteúdos trabalhados e criou sentido para o conceito de divisão enquanto "ideia de medir" baseado em elementos presente em sua realidade. Tais evidências foram constatadas porque, mesmo um ano após a realização das atividades, ela ainda conseguia fazer uma analogia entre o objeto material com que estava interagindo, o chocolate, e os conteúdos matemáticos que ela aprendeu.

\section{CONSIDERAÇÕES FINAIS}

Ao longo da pesquisa, observamos indícios da construção de conceitos nos planos material, da linguagem externa e mental, constituindo-se evidências de aprendizagem. Verificamos que o Material Pedagógico "Escala Algébrica" influenciou como mediador entre a aluna surda, o professor e o objeto de ensino em questão e atuou como potências do desenvolvimento mental da aluna surda.

A dinâmica desenvolvida com base na Teoria das Ações Mentais por Etapas com o uso da Escala Algébrica, proporcionou condições para Lia assimilasse os diferentes conceitos da divisão. Com o desenvolvimento desta atividade pudemos verificar que a aluna inicialmente tinha conhecimento da divisão enquanto um algoritmo e desconhecia os outros sentidos da divisão propostos por CENTURIÓN (2006). Desta forma, o uso do material pedagógico "escala algébrica" possibilitou que a aluna conseguisse compreender a divisão como a ideia de medir.

Com base nessas considerações, constatamos que os Materiais Pedagógicos tendem a contribuir para a construção de um sujeito sócio-histórico. Uma vez que, a gênese da teoria utilizada como base nesse estudo, indica que a aprendizagem se desencadeia da interação social, ou seja, a aquisição de conhecimento emerge da ação no plano material.

Todavia, é importante destacar que o uso dos Materiais Pedagógicos deve estar interligado com a proposta de ensino. Deve existir uma necessidade de sua utilização para que o 
desenvolvimento da atividade aconteça, caso contrário o uso dos Materiais Pedagógicos não estará atuando de forma direta no processo de aprendizagem do aluno. Além disso, precisamos ter consciência de que os Materiais Pedagógicos devem atuar em momentos específicos de uma atividade, e não podem ser a única fonte de conhecimento. Isso porque, sob de uma perspectiva sócio-histórica, o processo de desenvolvimento do sujeito se dá de fora para dentro, portanto deve-se haver a transição dos aspectos externos e matérias para os planos internos e mentais.

Ou seja, durante o processo de aprendizagem, os Materiais Pedagógicos devem dar lugar aos processos internos, pois essa transição é essencial para o ciclo de aprendizagem. Segundo Oliveira (1997, p. 35), "ao longo do processo de desenvolvimento, o indivíduo deixa de necessitar de marcas externas e passa a utilizar signos internos, isto é, representações mentais que substituem os objetos do mundo real".

Entretanto, segundo Nuñez e Pacheco (1998) não basta ver ou escutar algo relacionado com o tema objeto de estudo, é preciso fazer algo, realizar alguma ação com seu conteúdo. Foi, portanto, pela presença dos Materiais Pedagógicos que a aluna conseguiu realizar ação sobre os conteúdos. Ou seja, ela conseguiu construir e descontruir inferências referentes aos conteúdos matemáticos que, posteriormente possibilitaram que a mesma transformasse essa ação no plano material em representações mentais dos objetos reais.

Ao realizar a analogia do material escala algébrica com as barras de chocolate, Lia demonstrou a capacidade de fazer relações do conhecimento matemático com os elementos presentes no seu cotidiano. Além disso, a ação da Lia um ano após a realização da pesquisa nos indica que os diferentes conceitos de divisão trabalhados com a mediação da Escala Algébrica e permeados pela Teoria Galperiana foram construídos de forma consistente. 


\section{REFERÊNCIAS}

ARNOLDO-JUNIOR, Henrique. Estudo do desenvolvimento do pensamento geométrico por alunos surdos por meio do Multiplano no ensino fundamental. Porto Alegre, 2010. $290 \mathrm{f}$. Dissertação (Mestrado em Educação em Ciências e Matemática) - Faculdade de Física, PUCRS.

BASSAN, L. H. Teoria da formação das ações mentais por etapas, de P. Gasperin, e o processo de humanização. Marília, 2012.

CENTURIÓN, Marília. Conteúdo e metodologia da matemática: números e operações. São Paulo: Scipione, 2006.

DUARTE, D. M. $\mathbf{O}$ ensino do conceito de função afim: uma proposição com base na teoria de Galperin. Criciúma: Ed. do Autor, 2011.

GALPERIN, P.I. Mental actions as a basis for the formation of thoughts and images. Soviet Psychology, Moscou, v. 27, n. 3, p. 45- 64, may/june 1989.

GERDES, P. Sobre o despertar do pensamento geométrico. Curitiba: UFPR, 1992.

LOPES, M. C.; VEIGA-NETO, A. Marcadores Culturais surdos: quando eles se constituem no espaço. Em: Perspectiva. Florianópolis, v. 24, no Especial, 2006, p. 81 - 100.

Surdez \& Educação. 2ª ed. Belo Horizonte: Autêntica Editora, 2011.

NUÑEZ, I. B.; PACHECO, O. G. Formação de conceitos segundo a teoria de assimilação de Galperin. Cad. Pesquisa. № 105, p. 99 - 109. Nov, 1998.

REZENDE, A.; VALDES, H. Galperin: implicações educacionais da teoria de formação das ações mentais por estágios. Educ. Soc. [online]. 2006, vol.27, n.97, p. 1205-1232.

SANTOS, K. R. Educação especial e a escola: reflexões sobre os projetos educanionais para alunos surdos. Em: FERNANDES, Eulalia (org.). Surdez e Bilinguismo. Porto Alegre: Mediação, 2005, p. 51-64.

VIEIRA-MACHADO, L. M.C. Os surdos, os ouvintes e a escola: narrativas, traduções e históricas capixabas. Vitória: EDUFES, 2010.

VIGOTSKI, L. S. A construção do pensamento e linguagem. São Paulo: Martins. Fontes, 2001. 